WellBeing International

WBI Studies Repository

$2-22-2002$

\title{
Anatomical and Electrophysiological Analysis of the Trigeminal Nerve in a Teleost Fish, Oncorhynchus mykiss
}

Lynne U. Sneddon

Roslin Institute

Follow this and additional works at: https://www.wellbeingintlstudiesrepository.org/acwp_vsm

Part of the Animal Structures Commons, Animal Studies Commons, and the Veterinary Anatomy

Commons

\section{Recommended Citation}

Sneddon, L. U. (2002). Anatomical and electrophysiological analysis of the trigeminal nerve in a teleost fish, Oncorhynchusmykiss. Neuroscience letters, 319(3), 167-171.

This material is brought to you for free and open access by WellBeing International. It has been accepted for inclusion by an authorized administrator of the WBI Studies Repository. For more information, please contact wbisr-info@wellbeingintl.org.

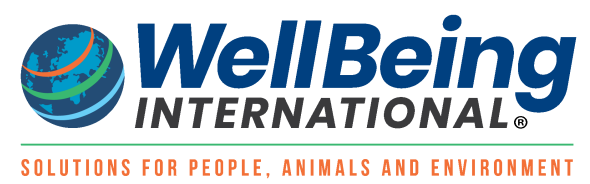




\title{
Anatomical and Electrophysiological Analysis of the Trigeminal Nerve in a Teleost Fish, Oncorhynchus mykiss
}

\author{
Lynne U. Sneddon \\ Roslin Institute
}

\section{KEYWORDS}

A-delta fibre, C fibre, Gasserian ganglion, rainbow trout, Oncorhynchus mykiss

\begin{abstract}
The trigeminal nerve in the rainbow trout, Oncorhynchus mykiss, was examined for the presence of Adelta and $C$ fibres. Sections of the three branches of the trigeminal nerve were found to comprise a range of fibre types including Adelta and $C$ fibres. The size range of the cell bodies of the trigeminal ganglion reflected the fibre range since they correlated with the size range of axons in the nerve branches. Electrophysiological recordings of evoked activity from the ganglion confirmed the presence of these fibre types and the proportion of these mirrored the proportion of fibre types in the anatomical analyses. A-beta fibres were most common followed by A-delta fibres, then A-alpha fibres with $C$ fibres being the fewest fibre type found. In higher vertebrates, A-delta and $C$ fibres in the trigeminal nerve convey both somatosensory and nociceptive information to the brain. The evolutionary significance of these results is discussed as well as the potential for nociceptive capability in a lower vertebrate.
\end{abstract}

In vertebrates precise somatosensory information about the changing environment an animal enters and explores is primarily via the head and mouth region. The skin of the head and mouth is mainly innervated by the trigeminal system. This somatosensory input augments both visual and auditory information and is of particular importance to nocturnal and burrowing animals. Trigeminal sensory afferents convey tactile and thermal information from the skin but also provide information about tissue damaging (noxious) stimuli. The ability to detect and react to potentially noxious stimuli is crucial to survival. Receptors that exclusively detect noxious stimuli are called nociceptors and have been extensively characterized in mammals and birds $[2,8]$. These receptors have free nerve endings and many are polymodal in that they respond to more than one noxious stimulus (e.g. heat, high mechanical pressure and noxious chemicals). In response to a noxious stimulus, a reflex response to move away from that stimulus is elicited as well as protective vegetative reactions. In birds and mammals it is well known that the nociceptive nerves can be divided into two classes: (1) small, slow conducting myelinated A-delta fibres and (2) smaller, slower conducting unmyelinated $C$ fibres. The trigeminal somatosensory system has not been systematically studied in fish especially in relation to nociception. Studies in elasmobranchs have suggested a general lack of $C$ fibres although A-delta fibres have been found as well as neurotransmitters in the dorsal horn $[5,10]$ which are known to be involved in pain mechanisms in higher vertebrates. There is evidence in 
lampreys that cutaneous nerves physiologically respond to the application of high mechanical pressure but there is no anatomical or behavioural evidence to support their nociceptive function [7]. There has been no work to investigate peripheral nociceptors in teleost fish [4]. The present study was carried out on the trigeminal nerve of the rainbow trout, Oncorhynchus mykiss, to determine if A-delta and C fibres are present that innervate the skin of the head and could potentially act as nociceptors. The objectives of this study are firstly to examine the trigeminal afferent nerves to determine whether A-delta and $C$ fibres are present in each of the trigeminal branches of the fish, secondly to determine the size of the cell bodies of these nerves which are present in the trigeminal (Gasserian) ganglion, and thirdly to confirm electrophysiologically A-delta and C fibre presence.

All experiments were performed on rainbow trout $(905 \pm 50 \mathrm{~g})$ which were supplied by Penicuik Trout Farm, Penicuik, Midlothian, UK. The fish were maintained in two black circular tanks (130 gallons; $n=5$ fish maximum per tank) with a constant flow of filtered freshwater at $15^{\circ} \mathrm{C}$. The fish were fed ad libitum daily and kept on a $12 \mathrm{~h}$ light/dark regime. Half of each tank was covered by an opaque cover to provide an area for sheltering.

Three fish were chosen at random and anaesthetized with MS222 (100 mg/l) and placed in a dorsal recumbent position in a sponge lined cradle. A constant flow of anaesthetic was maintained by intubating the mouth and allowing anaesthetic dosed water to pass over the gills. The abdomen of the fish was cut from the anal fin to the middle of the gill arches to expose the heart. The pericardium surrounding the heart was carefully cut away and a cannula (16 g) was inserted into the ventricle of the heart. The cannula passed through the atrium to the aorta. Saline $(0.9 \mathrm{~g} \mathrm{NaCl}$ in 1 I water) was perfused through the cannula using a peristaltic pump for approximately $20 \mathrm{~min}$ to remove the blood. After the saline the tissue was fixed in $2 \%$ glutaraldehyde in $0.075 \mathrm{M}$ sodium cacodylate buffer $(\mathrm{pH} 7.4)$ for $45 \mathrm{~min}$. Following fixation the fish was turned dorsal side up and the ophthalmic, maxillary and mandibular trigeminal nerves were carefully dissected out. They were placed into the glutaraldehyde fixative for a further hour and left overnight in $0.075 \mathrm{M}$ sodium cacodylate buffer at $4^{\circ} \mathrm{C}$.

Approximately $15 \mathrm{~h}$ later the nerves were placed in $1 \%$ osmium in $0.35 \mathrm{M}$ sodium cacodylate buffer for 1 $\mathrm{h}$, then transferred to $2 \%$ uranyl acetate (in 30\% acetone solution) and left for $1 \mathrm{~h}$. After this the nerves were embedded in SPURRS resin. The blocks containing the nerves were trimmed and $1 \mathrm{~mm}$ thick sections were cut on a LBK ultratome. The sections were mounted on slides and stained using $1 \%$ Toluidine Blue and viewed at a magnification of $x 1000$ using an Olympus light microscope. Few $C$ fibres were present and therefore it was decided that a full electron microscopy study would not be necessary. The sections were analyzed for the presence of unmyelinated and myelinated axons using the NIH Image Analysis Package for Macintosh. The number and diameter of axons were determined for all three afferents.

Another five rainbow trout were anaesthetized and perfused as described previously. The trigeminal ganglion was removed from either side of the brain and placed in formal alcohol acetic for 1 week. The ganglion was kept in orientation by allowing the neural tissue to adhere to small squares of cardboard before immersion in the fixative. The ganglion were embedded in the paraffin wax and $5 \mathrm{~mm}$ thick sections were mounted on polysine slides and stained with Cresyl Violet. The sections were viewed under a light microscope and analyzed using the NIH Image Program. The diameter of cells containing a nucleolus was measured and the number of cell bodies in the ganglion was calculated using the method of Coggeshall et al. [1].

Rainbow trout $(n=6)$ were anaesthetized by MS222 (50 mg/l), weighed and injected intraperitoneally with Saffan (0.3 ml/100 g; Schering-Plough Animal Health, Welwyn Garden City). Once the fish were deeply anaesthetized they were placed into a stainless steel cradle cushioned with wet paper towel and held in 
position with Velcro straps. The mouth was intubated with a rubber tube that delivered water as a spray and ensured water was flushed continuously over the gills. Heart rate was continuously monitored and the fish were kept in a stable condition till the termination of the experiment. The surgery took place on the right side of the head above the area of the trigeminal nerve entering the brain stem. The skin and bone were carefully removed to expose the trigeminal ganglion. The ganglion was desheathed and the area covered in paraffin to prevent moisture loss. Glass insulated tungsten microelectrodes with a tip diameter of $10 \mathrm{~mm}$ were used to record extracellular action potentials from the cell bodies in the ganglion. The electrical activity was amplified using a NL100 headstage connected to a NL104 preamplifier (Neurolog system, Digitimer Ltd., UK). The signal was displayed on a storage oscilloscope (5113, Tektronix INC) and stored on a PC using a Micro 1401 interface and Spike 2 software (CED, UK). Spontaneous and evoked activity were recorded and the durations of action potentials were calculated to determine what kind of fibres were present. Mechanical (von Frey hairs), thermal and noxious chemical ( $0.1 \%$ acetic acid) stimuli were applied to receptor areas located on the head and face of the trout to determine receptor type.

Fig. 1. (A) Section of the maxillary branch of the trigeminal nerve of the rainbow trout ( $x 400$, scale bar $=4$ $\mu \mathrm{m})$. (B) Section of the maxillary branch of the trigeminal nerve showing the presence of A-delta and $C$ fibres ( $x$ 1000, scale bar $=2 \mu \mathrm{m}$ ).

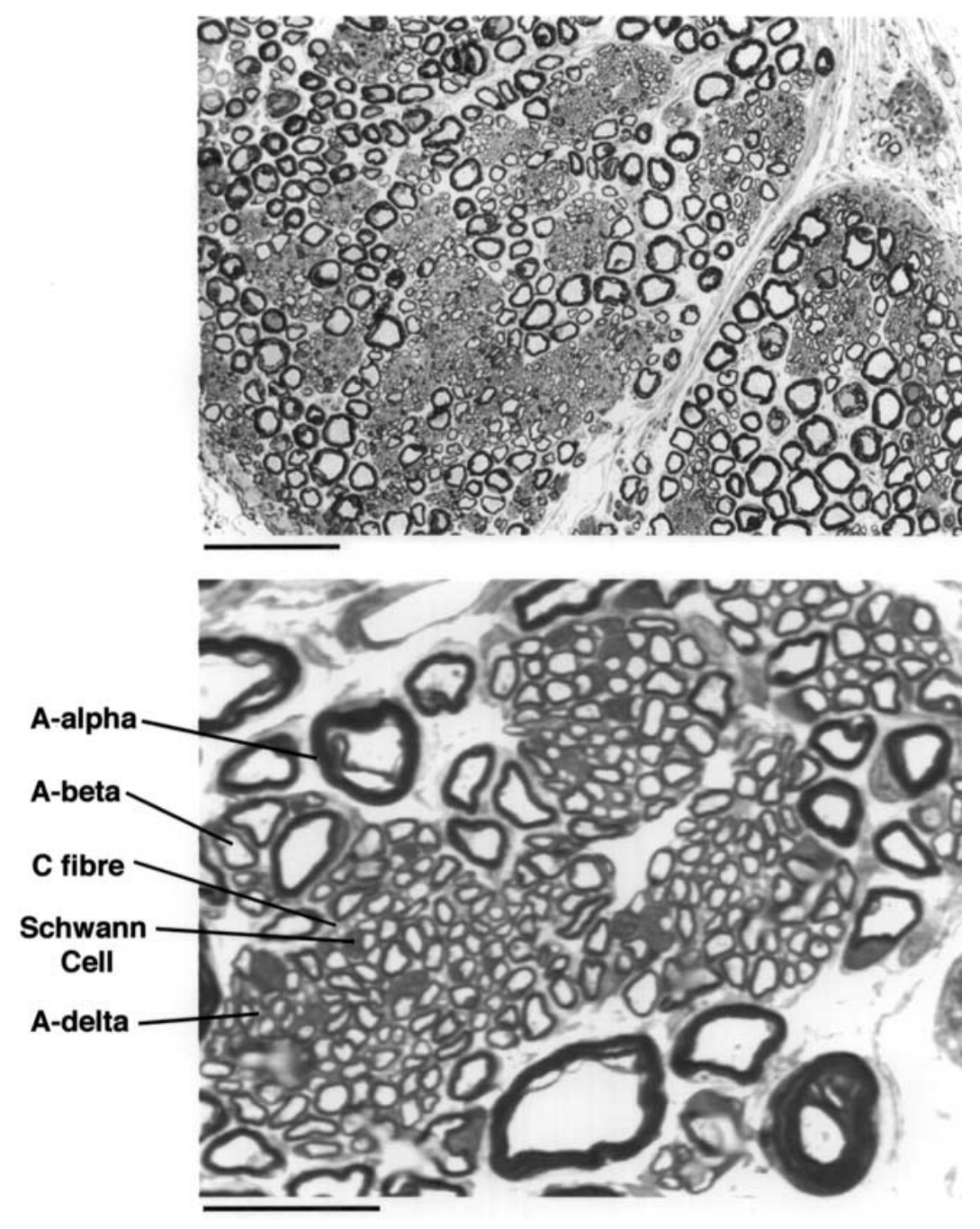


C fibres were found in all three branches of the trigeminal nerve (Fig. 1). The criteria used for determining the fibre type was based on the diameter of nerve fibres found in higher vertebrates [6]. The $C$ fibres were found in discrete bundles often associated with a Schwann cell and comprised approximately $4 \%$ of total fibre type (3.8\% ophthalmic, $4.1 \%$ maxillary and $4.1 \%$ mandibular). A-beta fibres were the most common (53\%) followed by A-delta (33\%) and Aalpha (9\%) fibres. C fibre diameter was characteristically between 0.1 and $1.2 \mu \mathrm{m}$. A-delta fibre diameter ranged from 0.4 to $5.8 \mu \mathrm{m}$, A-beta fibre diameter ranged from 6.0 to $12.1 \mu \mathrm{m}$ and A-alpha fibre diameter ranged from 12.1 to $20.2 \mu \mathrm{m}$.

Fig. 2. Section of the trigeminal ganglion showing a size range of cell bodies ( $x 400$, scale bar $=4 \mu \mathrm{m}$ ). Only cells that contained a nucleolus were measured in the analysis.

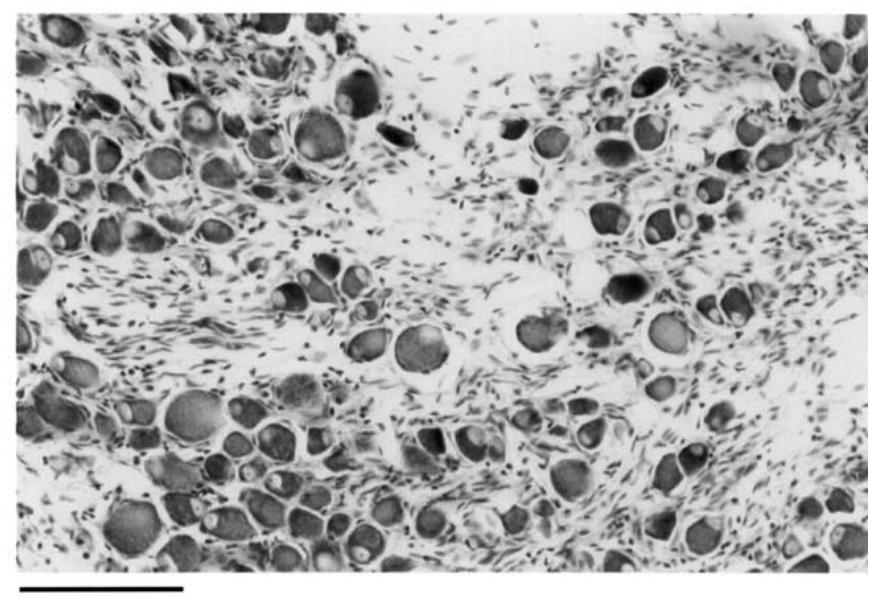

The ganglion of the fifth cranial nerve was characteristically a semi-lunar shape. It was closely apposed to the ventral, curving aspect of the posterior part of the optic tectum and was joined to the ventrolateral aspect of the pons by a thick sensory and thin motor root. The ophthalmic nerve arose from the medial aspect of the ganglion and ran rostromedially under the tectum. The mandibular and maxillary nerves arose from the anterior aspect of the ganglion and ran rostrally. It comprised cell bodies ranging in diameter from 7.9 to $37.5 \mu \mathrm{m}$ with a mean of $17.5 \mu \mathrm{m}$ (Fig. 2). Neither cell bodies of less than $10 \mu \mathrm{m}$ in diameter nor cell bodies greater than $35 \mu \mathrm{m}$ in diameter were abundant in the ganglion. Cell bodies of diameter 10-20 mm predominated (Fig. 2).

To examine if there was a relationship between cell body diameter and axon diameter, a regression analysis was performed on the diameter of the four fibre types and the diameter of the cell body sizes. There was a significant positive relationship between cell body size and fibre diameter $(y=10.22+1.54 x$, $r^{2}=0: 98 ; F_{1,2}=82.56, P=0.012$ ).

Trigeminal neural activity was recorded from all six fish. The number of action potentials per fish ranged from one to 12 different units as characterized by Spike 2 waveform analysis (Fig. 3). The duration of the action potentials ranged from 0.23 to $2.27 \mathrm{~ms}$ with the majority in the range of $0.67-1.90 \mathrm{~ms}$. There were fewer fast action potentials ( $<1 \mathrm{~ms}$ ) and only three types were greater than $2 \mathrm{~ms}$. Evoked activity demonstrated that there were fast adapting mechanoreceptors and polymodal slowly adapting mechanoreceptors that responded not only to mechanical stimulation but also to thermal and or chemical stimuli. 
Fig. 3. Action potentials recorded from four different units of the trigeminal nerve of the rainbow trout. (A) Fast adapting mechanoreceptor with an action potential duration of $0.8 \mathrm{~ms}$. 'On' denotes when the mechanical stimulus was applied and 'Off' denotes when the mechanical stimulus was removed. (B) Slowly adapting mechanoreceptor with an action potential duration of $1.9 \mathrm{~ms}$. (C) Polymodal slowly adapting mechanoreceptor responding to the application of a noxious chemical stimulus ( $0.1 \%$ acetic acid). The action potential duration was $1.9 \mathrm{~ms}$. (D) Polymodal slowly adapting mechanoreceptor responding to a thermal stimulus of $50^{\circ} \mathrm{C}$. The action potential duration was $2.0 \mathrm{~ms}$.
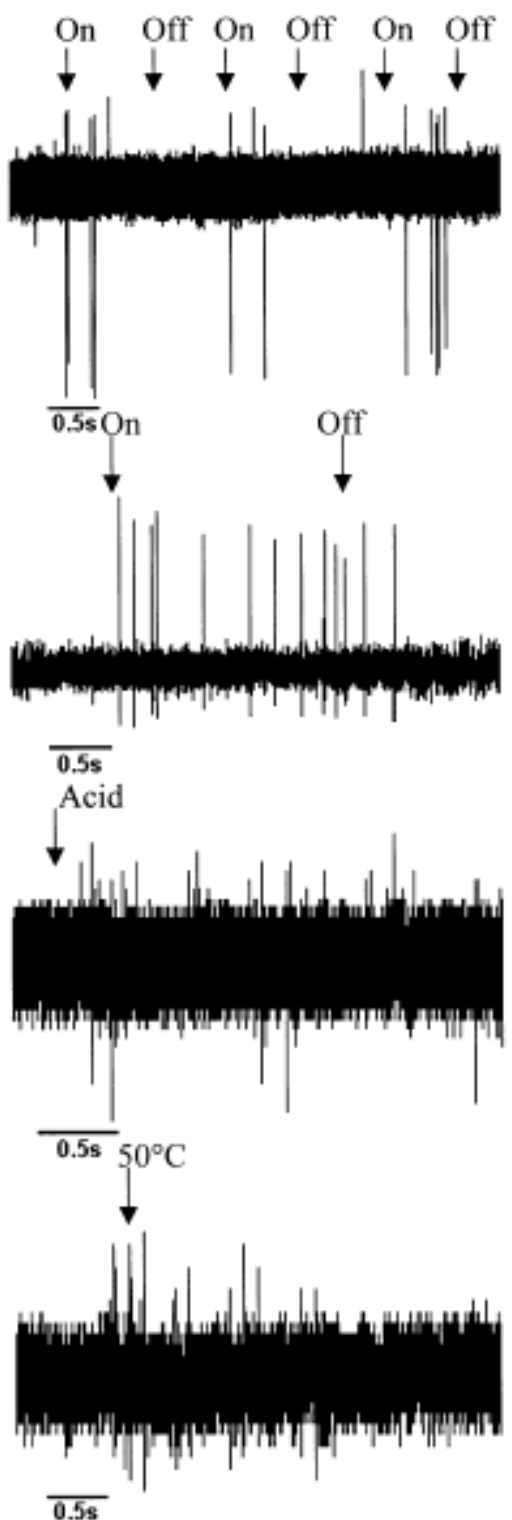

The trigeminal nerve is responsible for much of the somatosensory innervation of the face and head in vertebrates including man [9]. This important cranial nerve is involved with the common chemical sense when the receptors in the exposed or semi-exposed mucosal membranes respond to a wide variety of different chemical stimuli including algogenic substances [9]. In birds and mammals these polymodal nociceptors are found as free nerve endings within the mucous membrane and the primary afferent fibres are unmyelinated $\mathrm{C}$ fibres and the small myelinated A-delta fibres. Previous studies in fish have shown 
that the fish have free nerve endings beneath the epithelium [3] and the present study on the trout has demonstrated that the trigeminal nerve has both $C$ and A-delta fibres.

In man and other vertebrates $C$ fibres are distributed throughout the nerve and can comprise $50 \%$ (cat, man [15]) to $65 \%$ (frog [15]) of total fibre type. In the rainbow trout the C fibres were found in discrete bundles and only comprised $4 \%$ total fibre type. This considerably smaller proportion of $C$ fibres may be connected with the advance onto land in vertebrate evolution. Terrestrial animals are exposed to dramatic changes in temperature, noxious gases and increased chance of mechanical injury due to gravity. In the aquatic environment temperature fluctuations are relatively slight, buoyancy compensates for any gravitational effects and noxious chemicals may be highly diluted in some cases. Therefore, the requirement for a comprehensive nociceptive system may not be as essential as in terrestrial vertebrates, thus fish have less neural wiring dedicated to nociception. As animals evolved to a terrestrial existence, the increased exposure to noxious stimuli and new kinds of organisms, predators and prey, would drive the demand for a more sophisticated alarm system and thus an increase in the relative numbers of nociceptive nerves. Nociception has been reported in amphibians that have a relatively high number of $\mathrm{C}$ fibres [12]. In the stingray only $0.7-1.2 \%$ of fibres were $C$ fibres [10] and other evidence has suggested a lack of $\mathrm{C}$ fibres in other elasmobranch species [5]. It is interesting to note that a teleost fish, the rainbow trout, has a higher percentage of $C$ fibres compared with the elasmobranchs $[5,10]$. This may indicate an evolutionary divergence when teleosts evolved as a separate group from elasmobranchs. Leonard [5] suggested that nociception was not important in the elasmobranchs, however, they do posses the relevant neuromodulators associated with nociception (e.g. enkephalin activity in the spinal cord [11]; substance $P$ in the brain [13]) and they also possess A-delta fibres. There were a large number of A-delta fibres in the trigeminal nerve of the rainbow trout, therefore, they have the potential for nociceptive capabilities and in the rainbow trout enkephalin activity has been found in regions of the central nervous system particularly associated with pain processing [13]. The trigeminal nerve projects to the relevant brain areas, the thalamus, cerebellum and medulla, which are involved in pain or nociceptive processing in higher vertebrates. Fish are subject to noxious pollutants, unpalatable or poisonous food and also mouth injuries as a result of aggression, spiny prey and angling. It is conceivable that it would be adaptive for the animal to be able to perceive these potentially injurious stimuli and react appropriately.

The size range of each fibre type was similar to those found in other animals $[5,15]$. The cell bodies of the trigeminal ganglion were of a similar size to those found in man (10-60 $\mu \mathrm{m}$ [3]), birds (8-58 $\mu \mathrm{m}$ [14]) and in lampreys (25-50 $\mu \mathrm{m}$ [7]). This indicates that the basic components of the trigeminal nerve are similar in all vertebrates but only the relative number of fibre types that comprise the afferent nerves differ in fish.

The physiological recordings demonstrate that there were action potentials of slow duration that could potentially be A-delta and $C$ fibres in the rainbow trout trigeminal nerve. The results show that there are few A-alpha fibres ( $<0.35 \mathrm{~ms})$, a high number of A-beta and A-delta fibres $(0.35-2.0 \mathrm{~ms})$ and very few $\mathrm{C}$ fibres (>2.0 ms). Nociceptors are slowly adapting polymodal mechanoreceptors [8] and these receptor types were found on the head and face of the rainbow trout in this study. Therefore, the physiological recordings mirror the anatomical findings and show that there are fibres that could potentially act as nociceptive nerves. Further work should involve single unit recording to further characterize the type of receptors present on the face and mouth of the fish and to determine if they preferentially respond to noxious, potentially painful stimuli.

L.U.S. is grateful to Mike Gentle for his comments on this manuscript, Louise Dunn, Graeme Robertson, Sandra Wilson, Laura Dick and Linton Brown (Institute of Aquaculture, Stirling) for technical assistance, and to BBSRC (Grant No. 215/S11042) for funding. 
[1] Coggeshall, R.E., LaForte, R. and Klein, C.M., Calibration of methods for determining numbers of dorsal root ganglion cells, J. Neurosci. Methods, 35 (1990) 187-194.

[2] Gentle, M.J., Cutaneous sensory afferents recorded from the nervus intramandibularis of Gallus gallus var domesticus, J. Comp. Physiol. A, 164 (1989) 763-774.

[3] Harder, W., Anatomy of Fishes, E. Schweizerbart'sche Verlagsbuchhandlung, Stuttgart, 1975.

[4] Kestin, S.C., Pain and stress in fish. Report prepared for the Royal Society for the Prevention of Cruelty to Animals, 1994.

[5] Leonard, R.B., Primary afferent receptive field properties and neurotransmitter candidates in a vertebrate lacking unmyelinated fibres, Prog. Clin. Biol. Res., 176 (1985) 135-145.

[6] Lynn, B., The fibre composition of cutaneous nerves and the classification and response properties of cutaneous afferents, with particular reference to nociception, Pain Rev., 1 (1994) 172-183.

[7] Matthews, G. and Wickelgren, W.O., Trigeminal sensory neurons of the sea lamprey, J. Comp. Physiol. A, 123 (1978) 329-333.

[8] Meyer, R.A., Campbell, J.N. and Raja, S.N., Peripheral mechanisms of nociception, In P.D. Wall and R. Melzack (Eds.), Textbook of Pain, Churchill Livingstone, London, 1994, pp. 13-44.

[9] Silver, W.L. and Finger, T.E., The trigeminal system, In T.V. Getchell (Ed.), Smell and Taste in Health and Disease, Raven Press, New York, 1991, pp. 97-107.

[10] Snow, P.J., Plenderleith, M.B. and Wright, L.L., Quantitative study of primary sensory neurone populations of three species of elasmobranch fish, J. Comp. Neurol., 334 (1993) 97-103.

[11] Snow, P.J., Renshaw, G.M.C. and Hamlin, K.E., Localisation of enkephalin immunoreactivity in the spinal cord of the long tailed ray Himantura fai, J. Comp. Neurol., 367 (1996) 264-273.

[12] Spray, D.C., Pain and temperature receptors of anurans, In R. Llinas and W. Precht (Eds.), Frog Neurobiology, Springer Verlag, Berlin, 1976, pp. 607-628.

[13] Vecino, E. and Ekström, P., Distribution of met-enkephalin, leuenkephalin, substance P, neuropeptide $\mathrm{Y}, \mathrm{FMRFamide}$ and serotonin immunoreactivities in the optic tectum of the Atlantic salmon (Salmo salar L.), J. Comp. Neurol., 299 (1990) 229-241.

[14] Wild, J.M. and Zeigler, H.P., Central projections and somatotopic organisation of the trigeminal primary afferents in pigeon (Columba livia), J. Comp. Neurol., 368 (1996) 136-152.

[15] Young, R.F., Fiber spectrum of the trigeminal sensory root of frog, cat and man determined by electron microscopy, In D.L. Anderson and B. Matthews (Eds.), Pain in the Trigeminal Region, Elsevier, Amsterdam, 1977, pp. 137-160. 